\title{
Prevalence of obesity and overweight in Iranian children aged less than 5 years: a systematic review and meta-analysis
}

\begin{abstract}
Kamyar Mansori, PhD ${ }^{1,2}$, Sorour Khateri, MD², Yousef Moradi, PhDc ${ }^{4}$, Zaher Khazaei, MSc ${ }^{5}$, Hossein Mirzaei, PhDc ${ }^{6}$, Shiva Mansouri Hanis, $\mathrm{MS}^{7}$, Mehran Asadi Aliabadi, PhDc ${ }^{8}$, Mehdi Ranjbaran, PhDc ${ }^{9}$, Fatemeh Varse, MSc ${ }^{10}$, Serveh Parang, MSc ${ }^{11}$

${ }^{1}$ Student Research Committee, Dezful University of Medical Sciences, Dezful, ${ }^{2}$ Department of Epidemiology, School of Public Health, Iran University of Medical Sciences, Tehran, ${ }^{3}$ Student Research Committee, Kurdistan University of Medical Sciences, Sanandaj, ${ }^{4}$ Student Research Committee, School of Public Health, Iran University of Medical Sciences, Tehran, ${ }^{5}$ Student Research Committee, Sabzevar University of Medical Science, Sabzevar, ${ }^{6}$ Department of Biostatistics and Epidemiology, School of Public Health, Kerman University of Medical Sciences, Kerman, ${ }^{7}$ School of Public Health and Safety, Shahid Beheshti University of Medical Sciences, Tehran, ${ }^{8}$ Preventive Medicine and Public Health Research Center, School of Medicine, Iran University of Medical Sciences, Tehran, ${ }^{9}$ Department of Epidemiology and Biostatistics, School of Public Health, Tehran University of Medical Sciences, Tehran, ${ }^{10}$ Department of Epidemiology, School of Public Health, Iran University of Medical Sciences, Tehran, "Department of Midwifery, Faculty of Nursing and Midwifery, Kurdistan University of Medical Sciences, Sanandaj, Iran
\end{abstract}

Purpose: The present study aimed to determine the prevalence of childhood obesity and overweight in Iranian children under 5 years of age using a systematic review and meta-analysis.

Methods: We searched MEDLINE (PubMed), Web of Science, Google Scholar, Scopus, CINHAL, and the Iranian databases, including Scientific Information Database (www.sid. ir), Iranian Research Institute for Information Science and Technology (Irandoc.ac.ir), Iranmedex (www.iranmedex.com), and Magiran (www.magiran.com), for all articles published between January 1989 and August 2017. Sources of heterogeneity were determined using subgroup analysis and meta-regression.

Results: Six articles were ultimately included in the meta-analysis to estimate the pooled prevalence, based on which the prevalence of obesity and overweight were estimated to be $8 \%$ (95\% confidence interval [Cl], $6 \%-10 \%)$ and $9 \%(95 \% \mathrm{Cl}, 7 \%-11 \%)$, respectively. The results of the subgroup analysis showed that the prevalence of obesity in boys and girls was $9 \%(95 \% \mathrm{Cl}, 6 \%-13 \%)$ and $7 \%(95 \% \mathrm{Cl}$, $4-10 \%)$, respectively, and the prevalence of overweight in boys and girls was $10 \%(95 \% \mathrm{Cl}, 5 \%-15 \%)$ and $9 \%(95 \% \mathrm{Cl}, 5 \%-13 \%)$, respectively.

Conclusion: Despite high heterogeneity among the results of the articles included in the meta-analysis, the prevalence of obesity and overweight is higher in Iranian children under 5 years of age. Therefore, parents and the health system must pay more attention to the lifestyle, nutritional habits, and physical activity of these children.

Key words: Prevalence, Overweight, Obesity, Child

\section{Key message}

It first, this study provides research evidence on the pooled of obesity and overweight among Iranian children aged less than 5 years. Our results highlighted that the pooled prevalence of obesity and overweight in Iranian children under 5 years of age was $8 \%(95 \% \mathrm{Cl}, 6 \%-10 \%)$ and $9 \%(95 \% \mathrm{Cl}, 7 \%$ $11 \%$ ), respectively. Therefore, parents and healthcare providers must pay more attention to the lifestyle, nutritional habits, and physical activity of Iranian children.
Corresponding author: Yousef Moradi, BS, MSc, $\mathrm{PhD}$

Student Research Committee, School of Public Health, Iran University of Medical Sciences, Tehran 009821, Iran

Tel: +989183847065

Fax: +982186700000

E-mail: yousefmoradi211@yahoo.com

https://orcid.org/0000-0002-2936-5930

Received: 8 November, 2018

Revised: 31 March, 2019

Accepted: 22 April, 2019 


\section{Introduction}

The prevalence of childhood obesity and overweight has increased significantly in developed and developing countries over the past few decades and will most likely continue to increase.". A study assessed the global burden of obesity and overweight in 2005 and reported that the total number of overweight and obese people is 937 million (23.2\%) and 396 million (24.0\%), respectively, and the number of overweight and obese people is expected to increase to 1.35 billion and 573 million, respectively, in 2030. ${ }^{2)}$ Childhood obesity may causes problems, such as high blood pressure, blood lipid disorders, chronic inflammation, an increased tendency to develop blood clots, endothelial dysfunction, and increased blood insulin levels. ${ }^{3,4)}$ Early childhood is an important time to examine the determinants of childhood obesity because most habits related to physical activity, nutrition, and lifestyle are formed during this period. Studies have reported that many cases of adult obesity originate in childhood; therefore, obesity is an important predictor of allcause death and disease prevalence in adulthood, while childhood obesity is a major concern among health professionals. ${ }^{5-7)}$

The epidemiological transition and worldwide changes in lifestyle, especially in the Middle East, led to a significantly increased prevalence of overweight and obesity. The major disease burden consists of non-communicable diseases, particularly cardiovascular diseases and cancers. Iran, as a country in this region, has a high prevalence of obesity and its related disorders in different age groups, which imposes significant costs on the country's health care system. ${ }^{8-12)}$ Therefore, awareness of the prevalence of obesity and overweight, especially in children, can provide important information to health policymakers for designing and implementing prevention programs. ${ }^{13)}$ In contrast, improving physical fitness is an important public health factor to reduce the prevalence of lifestylerelated diseases in developed and developing countries. ${ }^{14,15}$

In recent years, several studies conducted on the prevalence of obesity and overweight in Iranian children have reported controversial results that have raised a variety of questions about the prevalence of obesity and overweight. Therefore, the present systematic review and meta-analysis aimed to determine the prevalence of childhood obesity and overweight in Iran.

\section{Materials and methods}

\section{Search strategy}

All original articles were searched from international databases including MEDLINE (PubMed), Web of Science, Google Scholar, Scopus, CINHAL, and the Iranian databases including the Scientific Information Database (www.sid.ir), Iranian Research Institute for Information Science and Technology (Irandoc.ac.ir), Iranmedex (www.iranmedex.com), and Magiran (www.magiran.com). We
Table 1. Search strategy

PubMed/MEDLINE

((“Malnutrition" [tiab] OR "Growth Disorders" [tiab]) AND (Overweight [tiab] OR Obesity [tiab] OR Body Weight [tiab]) AND (Children [tiab] OR "Children under 5 years" [tiab]) AND ("Iran" [Mesh] OR "Iran" [All Fields]) OR Iranian [All Fields] OR I.R. Iran [All Fields] OR "I.R Iran" [All Fields] OR ("persia" [MeSH Terms] OR "persia" [All Fields])) AND ((“1989/01/01" [PDAT: "2017/8/31" [PDAT]).

ISI Web of Science

Time span=1989-2017. Databases=SCI-EXPANDED, SSCI, CPCI-S, CPCI-SSH. Topic= ("Malnutrition" OR "Growth Disorders") AND (Overweight OR Obesity OR Body Weight) AND (Children OR "Children under 5 years") AND (("Iran" OR Iranian OR I.R. Iran OR "persia") OR Address= (Iran))

Scopus

(TITLE-ABS-KEY ("Malnutrition" OR "Growth Disorders") AND (Overweight OR Obesity OR Body Weight)) AND (TITLE-ABS-KEY (Children OR "Children under 5 years")) AND (TITLE-ABS-KEY (Iran OR Iranian OR I.R. Iran OR Persia) OR (AFFIL (Iran)) AND PUBYEAR > 1989 AND PUBYEAR < 2017

searched these engines without language or time limitations for articles published between January 1989 and June 2018. The search was performed using 8 keywords in English and Persian including Malnutrition, PEM (Protein Energy Malnutrition), Growth Disorders, Overweight, Obesity, Body Weight, Children under 5 years, and Children. All keywords were searched electronically using 2 Boolean operators with separate search strategies (Table 1).

\section{Inclusion/exclusion criteria}

We investigated the search results and then excluded some studies after title review. In the present study, the identified studies were evaluated by 2 reviewers individually (MY and MK) based on the inclusion and exclusion criteria. The PRISMA (Preferred Reporting Items for Systematic Reviews and Meta-Analyses) statement was used as a guide to enhance the reporting quality of this review. In this study, the inclusion criteria were: (1) cross-sectional study design; (2) estimated prevalence of growth disorders, overweight, obesity, and body weight; (3) sample age less than 5 years. The exclusion criteria were: (1) other study design except cross-sectional; (2) animal study; and (3) sample age older than 5 years.

\section{Data extraction, quality assessment, and risk of bias}

Study quality was assessed by the Modified Newcastle-Ottawa Scale for cross-sectional studies ${ }^{16,17)}$ and PRISMA checklist. ${ }^{18,19)}$ Two authors (MY and MK) independently reviewed the retrieved studies. After evaluation by the reviewing team, articles from our checklist included the following factors: (1) first author; (2) publication date; (3) date of study; (4) total sample size; (5) sampling method; (6) study design; (7) sample size (female versus male); (8) questionnaire type; (9) appraisal tool score; (10) main variable; (11) prevalence of malnutrition, growth disorders, overweight, obesity, and body weight based on a variety of questionnaires; and (12) inclusion criteria. 


\section{Statistical analysis}

We used a random effects model to generate a pooled prevalence presented as percentage and 95\% confidence interval (CI). Inter study heterogeneity was assessed using the $I^{2}$ heterogeneity statistic and reported as a percentage (\%) to determine the extent of inter study variation. A subgroup analysis was conducted based on sex, while a meta-regression was performed to examine the impact of publication year on prevalence. A forest plot was used to schematically present the meta-analysis results. All analyses were performed using Stata ver. 14 (Stata Corp, College Station, TX, USA).

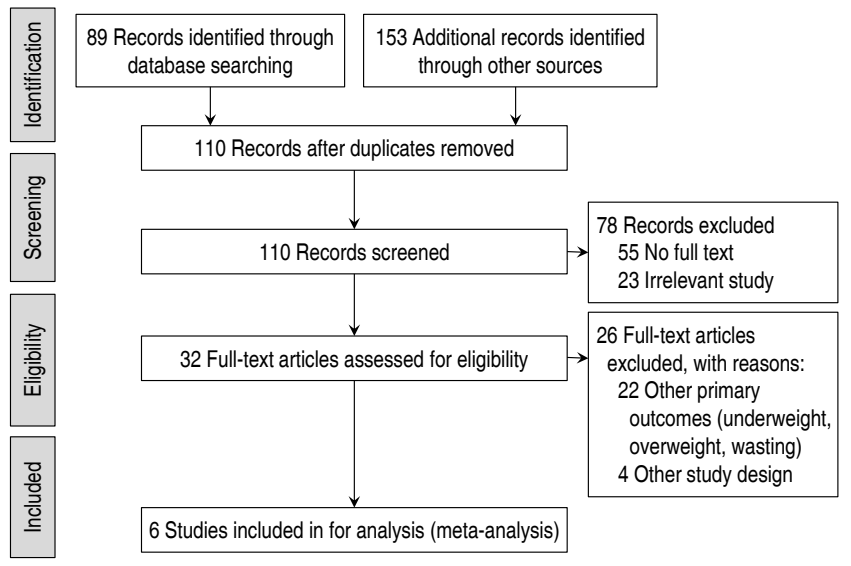

Fig. 1. Flow diagram of the literature search and study selection process.

\section{Results}

In the present study, 242 articles were identified according to the search strategy. After the exclusion of 132 duplicate articles, 110 articles were reviewed; of them, 78 were excluded because of lack of full text or no relevance. The full text of the remaining 32 articles was evaluated based on the developed checklist; finally, 6 articles were included in the meta-analysis (Fig. 1, Table 2). The reviewed studies were published between 2005 and 2014. The sample sizes of these studies varied from 400 to 1417 subjects.

\section{Assessment of pooled prevalence}

Six studies were evaluated in this meta-analysis to estimate the pooled prevalence of obesity and overweight in Iranian children under 5 years of age.

The study results showed that the pooled prevalence of obesity in Iranian children under 5 years of age was 8\% (95\% CI, 6\%-10\%). The $I^{2}$ index was used to illustrate the heterogeneity of the studies included in the meta-analysis, and the results indicated a high heterogeneity among studies included to estimate the pooled prevalence of obesity $\left(I^{2}, 99.7 \%, P<0.001\right)$. The results of the subgroup analysis of sex showed that the prevalence of obesity in Iranian boys and girls under 5 years of age was 9\% (95\% CI, 6\%-13\%) and 7\% (95\% CI, 4\%-10\%), respectively. It should be mentioned that the $I^{2}$ index implied high interstudy heterogeneity between boys $\left(I^{2}, 99.5 \%\right.$; $P<0.001)$ and girls $\left(I^{2}, 99.8 \% ; P<0.001\right)$ (Fig. 2$)$.

The findings of this study indicated that the pooled prevalence of

Table 2. Characteristics of the studies included in the meta-analyses

\begin{tabular}{|c|c|c|c|c|c|c|c|c|}
\hline \multirow{2}{*}{ Study } & \multirow{2}{*}{ Year } & \multirow{2}{*}{ Sample size } & \multirow{2}{*}{ Type of study } & \multirow{2}{*}{ City } & \multirow{2}{*}{ Measurement's } & \multirow{2}{*}{ Sex } & \multicolumn{2}{|c|}{ Prevalence (\%) } \\
\hline & & & & & & & Overweight & Obesity \\
\hline \multirow[t]{3}{*}{ Talaie-Zanjani et al. ${ }^{44)}$} & 2011 & 742 & Cross sectional & Arak & NCHS/WHO & Male & 9.85 & 6.27 \\
\hline & & & & & & Female & 7.86 & 3.19 \\
\hline & & & & & & Total & 8.76 & 4.58 \\
\hline \multirow[t]{3}{*}{ Akhavan-Karbasi et al. ${ }^{45)}$} & 2008 & 400 & Cross sectional & Yazd & NCHS/WHO & Male & 5.0 & 5.5 \\
\hline & & & & & & Female & 3.5 & 2.0 \\
\hline & & & & & & Total & 4.25 & 3.75 \\
\hline \multirow[t]{3}{*}{ Fatemeh et al. ${ }^{46)}$} & 2014 & 500 & Cross sectional & South Khorasan & NCHS/WHO & Male & - & - \\
\hline & & & & & & Female & - & - \\
\hline & & & & & & Total & - & 7.6 \\
\hline \multirow[t]{3}{*}{ Houshiar Rad et al. ${ }^{47)}$} & 2008 & 1,417 & Cross sectional & Iran & NCHS/WHO & Male & 4.5 & - \\
\hline & & & & & & Female & 5.9 & - \\
\hline & & & & & & Total & 5.2 & - \\
\hline \multirow[t]{3}{*}{ Nouhjah et al. ${ }^{48)}$} & 2011 & 1,035 & Cross sectional & Ahvaz & NCHS/WHO & Male & 16.7 & 9.0 \\
\hline & & & & & & Female & 13.3 & 5.6 \\
\hline & & & & & & Total & 15.0 & 7.3 \\
\hline \multirow[t]{3}{*}{ Sharabi et al. ${ }^{49}$} & 2005 & 1,042 & Cross sectional & Tehran & NCHS/WHO & Male & 13.55 & 16.20 \\
\hline & & & & & & Female & - & 17.51 \\
\hline & & & & & & Total & - & 16.96 \\
\hline
\end{tabular}


overweight in Iranian children under 5 years of age was 9\% (95\% CI, 7\%-11\%). As shown in Fig. 3, the $I^{2}$ index showed high interstudy heterogeneity $\left(I^{2}, 95.6 \% ; P<0.001\right)$. The results of the subgroup analysis based on sex showed that the prevalence of overweight in Iranian boys and girls under 5 years of age was 10\% (95\% CI, 5\%15\%) and 9\% (95\% CI, 5\%-13\%), respectively. It should be noted that the $I^{2}$ index indicated high interstudy heterogeneity for boys $\left(I^{2}\right.$, 99.5\%; $P<0.001)$ and girls $\left(I^{2}, 99.8 \% ; P<0.001\right)$ (Fig. 3).

\section{Meta-regression}

Meta-regression analysis was used to explore the sources of interstudy heterogeneity, including gender. The results of this this analysis showed that the prevalence of overweight and obesity was not related to gender $(B=-0.00073 ; P=0.875 ; 95 \% \mathrm{CI},-0.010$ to 0.009).

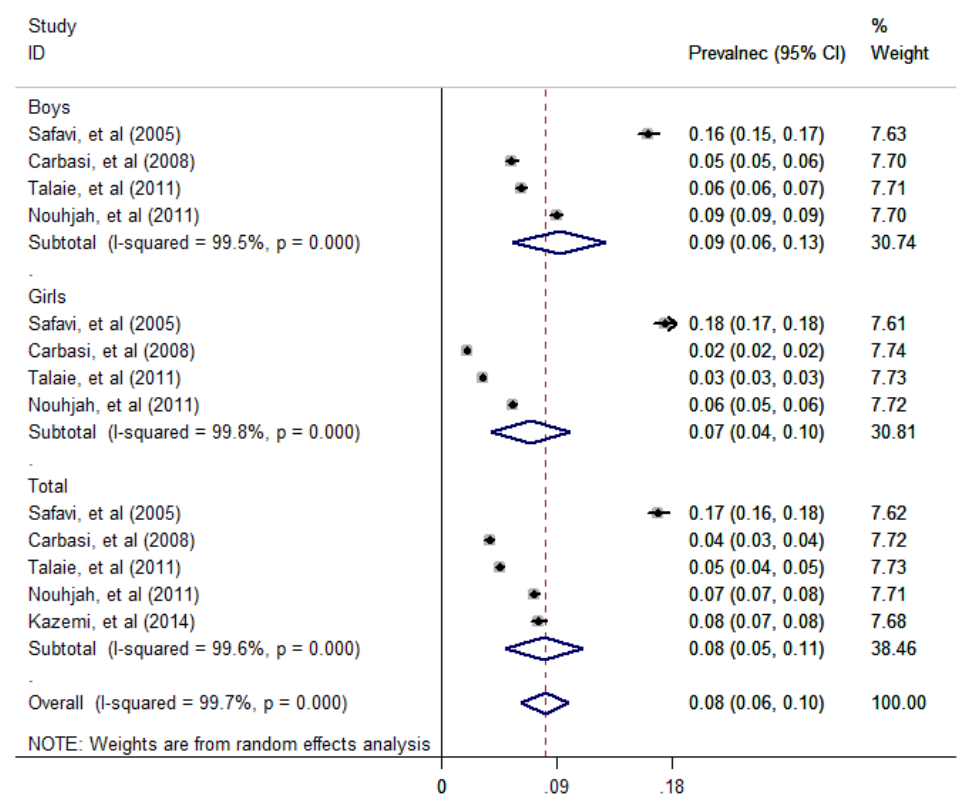

Fig. 2. Meta-analysis of the prevalence of obesity in Iranian children by sex. $\mathrm{Cl}$, confidence interval.

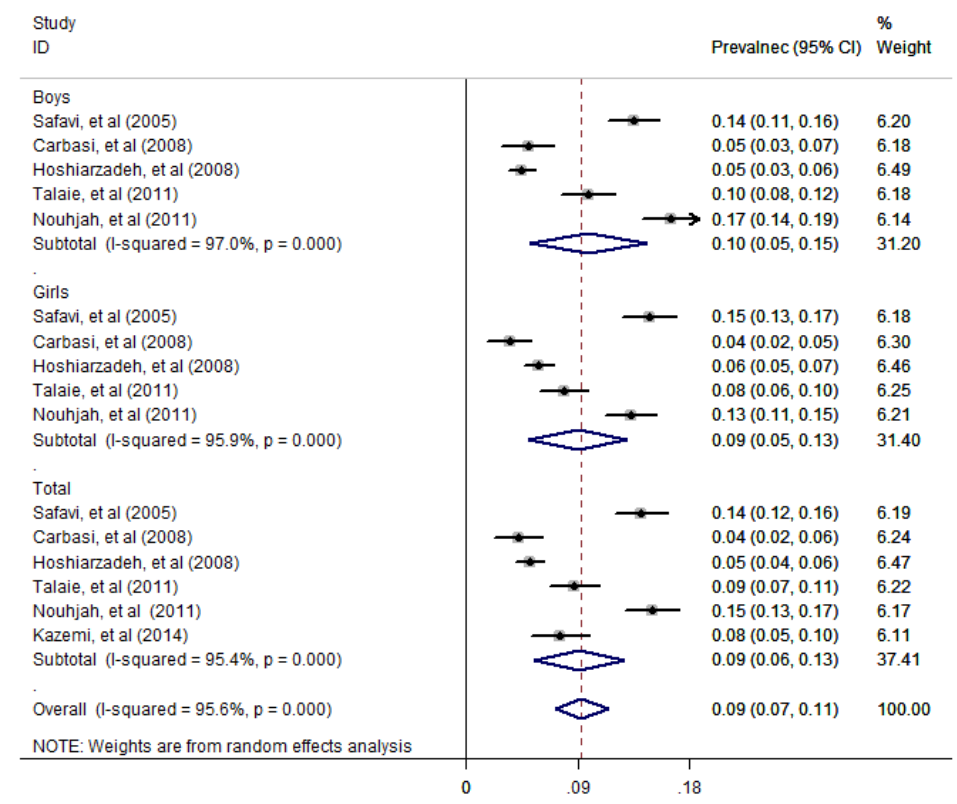

Fig. 3. Meta-analysis of the prevalence of overweight in Iranian children by sex. $\mathrm{Cl}$, confidence interval. 


\section{Discussion}

The present systematic review and meta-analysis aimed to determine the prevalence of obesity and overweight in Iranian children under 5 years of age. The study results showed that the pooled prevalence of obesity and overweight in Iranian children under 5 years of age was 8\% (95\% CI, 6\%-10\%) and 9\% (95\% CI, 7\%-11\%), respectively, regardless of sex. A study by Kelishadi et al. ${ }^{13)}$ that aimed to determine the prevalence and trends of childhood obesity and overweight in Iran showed that the prevalence of childhood obesity was approximately 5.1\%, and it remained constant between 2004 and 2010, regardless of sex. However, the sex-specific prevalence increased during this period, as follows: the prevalence of obesity in girls increased from $4.8 \%$ to $5.8 \%$, while that in boys increased from 5.8\% to 7.5\%. In a population-based cross-sectional study by Salehiniya et al., ${ }^{20)}$ the prevalence of overweight and obesity among children below 5 years of age was $12 \%$ and $23.7 \%$, respectively in Tehran in 2012. Hajian-Tilaki and Heidari ${ }^{21)}$ reported that the prevalence of overweight and obesity was $11.8 \%$ and 15\% in preschool children aged 2-5 years in the urban area of Babol (Iran) in 2013. The study by Karimi and Ghorbani ${ }^{22)}$ that aimed to determine the prevalence of overweight and obesity among schoolchildren in Semnan Province (Iran) showed that 8.2\% and $11.5 \%$ of schoolchildren have obesity and overweight, respectively. A study in the United States showed that the prevalence of obesity and overweight in children was 31.7\% and 16.9\%, respectively. Another study in the same country stated that $25.6 \%$ of children are obese. ${ }^{23,24)}$ A study in Pakistan also showed that 7.5\% of children are obese and 17\% are overweight. ${ }^{25)}$ Generally, although various studies showed that the estimated prevalence of overweight and obesity differs worldwide and may vary according to the definition of the population under study, definitions of obesity and overweight, sample size, and sampling methods, most studies have shown an increasing trend in prevalence. ${ }^{2,26)}$ For example, de Onis et al. ${ }^{27)}$ reported a worldwide increasing trend in the prevalence of obesity and overweight in children under 5 years of age over 1990-2010. Thus, along with changes in lifestyle and global industrialization, the prevalence of obesity and overweight has increased significantly in children.

Generally, compared with other studies in this field, ${ }^{28-30)}$ we noted an increase in the prevalence of obesity and overweight in Iranian children. This finding may reflect an epidemiological transition along with significant nutritional changes in Iranian children due to increased caloric intake and fast food consumption, increased time spent watching television and playing computer games, decreased physical activity, increased consumption of snacks when watching television, increasing number of television commercials about ready-made foods, and a lack of facilities for physical activity and outdoor play for children. ${ }^{31-33)}$ Considering that the nutritional status of children under 5 years of age is an important indicator of a community's health status and considering the outcomes and complications associated with obesity and overweight in adulthood and the increased nutritional changes in Iran and their implications, ${ }^{26)}$ careful planning and implementation of interventions and prevention programs are necessary to reduce and eliminate these complications at the community level.

This study showed that the prevalence of obesity in Iranian boys and girls under 5 years of age was 9\% (95\% CI, 6\%-13\%) and 7\% (95\% CI, 4\%-10\%), respectively, while the prevalence of overweight in boys and girls of the same age group was 10 (95\% CI, 5\%-15\%) and 9\% (95\% CI, 5\%-13\%), respectively. The prevalence of obesity and overweight was higher in boys than in girls in our study. This result is inconsistent with those of some other studies in this field. Salehiniya et al. ${ }^{20)}$ showed that the prevalence of overweight was higher in girls than in boys (13.6\% vs. 10.6\%), while the prevalence of obesity was higher in boys than in girls (26.4\% vs. $20.9 \%$ ). This study also reported a significant association between sex and the prevalence of obesity and overweight. The study by Majid et al. ${ }^{34)}$ in Ahwaz (Iran) revealed that the prevalence of obesity is higher in girls than in boys. A study in Australia also indicated that the prevalence of obesity and overweight was significantly higher in girls than in boys $\left(29.6 \% \pm 1.4 \%\right.$ vs. $23.9 \% \pm 1.3 \%$, respectively; $\chi^{2}=9.01$; $P=0.003) .{ }^{35)}$ However, other studies reported that the prevalence of obesity was higher in boys than in girls; these results are consistent with those of our study. For example, the study by Amini et $\mathrm{al}^{36}{ }^{36}$ in Tehran (Iran) showed that the prevalence of obesity among boys was twice as high as that among girls and that the difference was statistically significant. Another study in Babol (Iran) showed that the prevalence of obesity and overweight in girls was significantly lower than that in boys. ${ }^{37)}$ Studies have generally reported that sexbased differences may be due to various factors, such as differences in nutritional status, hormone levels, physiological and behavioral characters, and socioeconomic status. Cultural differences and sexbased differences can affect a child's nutritional status, health, and care. ${ }^{34,38-42)}$ In the present study, the attitude of the Iranian people towards obesity and overweight in boys and girls and their degree of sensitivity to fitness can explain the higher prevalence of overweight and obesity in boys than in girls because obesity and overweight are less socially acceptable in girls than in boys. ${ }^{43)}$

In conclusion, our results highlighted that the pooled prevalence of obesity and overweight in Iranian children under 5 years of age was 8\% (95\% CI, 6\%-10\%) and 9\% (95\% CI, 7\%-11\%), respectively. Despite high heterogeneity among the results of the articles included in this meta-analysis, the prevalence of obesity and overweight is higher in Iranian children under 5 years of age. Therefore, parents and healthcare providers must pay more attention to the lifestyle, nutritional habits, and physical activity of Iranian children. 


\section{Conflicts of interest}

No potential conflict of interest relevant to this article was reported.

\section{References}

1. Iacusso C, Bagolan P, Bottero S, Conforti A, Morini F. Postpneumonectomy syndrome in a newborn after esophageal atresia repair. Int $\mathrm{J}$ Surg Case Rep 2015;10:142-5.

2. Kelly T, Yang W, Chen CS, Reynolds K, He J. Global burden of obesity in 2005 and projections to 2030. Int J Obes (Lond) 2008;32:1431-7.

3. Ebbeling CB, Pawlak DB, Ludwig DS. Childhood obesity: publichealth crisis, common sense cure. Lancet 2002;360:473-82.

4. Reilly JJ. Descriptive epidemiology and health consequences of childhood obesity. Best Pract Res Clin Endocrinol Metab 2005;19: 327-41.

5. Crawford PB, Story M, Wang MC, Ritchie LD, Sabry ZI. Ethnic issues in the epidemiology of childhood obesity. Pediatr Clin North Am 2001;48:855-78.

6. Togashi K, Masuda H, Rankinen T, Tanaka S, Bouchard C, Kamiya H. A 12-year follow-up study of treated obese children in Japan. Int J Obes Relat Metab Disord 2002;26:770-7.

7. Trost SG, Sirard JR, Dowda M, Pfeiffer KA, Pate RR. Physical activity in overweight and nonoverweight preschool children. Int J Obes Relat Metab Disord 2003;27:834-9.

8. Wild S, Roglic G, Green A, Sicree R, King H. Global prevalence of diabetes: estimates for the year 2000 and projections for 2030. Diabetes Care 2004;27:1047-53.

9. Mehio Sibai A, Nasreddine L, Mokdad AH, Adra N, Tabet M, Hwalla N. Nutrition transition and cardiovascular disease risk factors in Middle East and North Africa countries: reviewing the evidence. Ann Nutr Metab 2010;57:193-203.

10. Delavari A, Forouzanfar MH, Alikhani S, Sharifian A, Kelishadi R. First nationwide study of the prevalence of the metabolic syndrome and optimal cutoff points of waist circumference in the Middle East: the national survey of risk factors for noncommunicable diseases of Iran. Diabetes Care 2009;32:1092-7.

11. Haghdoost AA, Rezazadeh-Kermani M, Sadghirad B, Baradaran HR. Prevalence of type 2 diabetes in the Islamic Republic of Iran: systematic review and meta-analysis. East Mediterr Health J 2009;15:5919.

12. Kelishadi R, Ardalan G, Gheiratmand R, Adeli K, Delavari A, Majdzadeh R, et al. Paediatric metabolic syndrome and associated anthropometric indices: the CASPIAN Study. Acta Paediatr 2006;95:162534.

13. Kelishadi R, Haghdoost AA, Sadeghirad B, Khajehkazemi R. Trend in the prevalence of obesity and overweight among Iranian children and adolescents: a systematic review and meta-analysis. Nutrition 2014; 30:393-400.

14. Raustorp A, Pangrazi RP, Ståhle A. Physical activity level and body mass index among schoolchildren in south-eastern Sweden. Acta Paediatr 2004;93:400-4.

15. Fulton JE, Burgeson CR, Perry GR, Sherry B, Galuska DA, Alexander MP, et al. Assessment of physical activity and sedentary behavior in preschool-age children: priorities for research. Pediatr Exerc Sci 2001;13:113-26.

16. Wells G, Shea BJ, O'Connell D, Peterson J. The Newcastle-Ottawa Scale (NOS) for assessing the quality of nonrandomised studies in meta-analysis. Eur J Epidemiol 2011;25:603-5.

17. Stang A. Critical evaluation of the Newcastle-Ottawa scale for the assessment of the quality of nonrandomized studies in meta-analyses. Eur J Epidemiol 2010;25:603-5.

18. Moher D, Liberati A, Tetzlaff J, Altman DG; PRISMA Group. Preferred reporting items for systematic reviews and meta-analyses: the PRISMA statement. Int J Surg 2010;8:336-41.

19. Moher D, Shamseer L, Clarke M, Ghersi D, Liberati A, Petticrew M, et al. Preferred reporting items for systematic review and meta-analysis protocols (PRISMA-P) 2015 statement. Syst Rev 2015;4:1.

20. Salehiniya H, Yazdani K, Barekati H, Asadi Lari M. The Prevalence of overweight and obesity in children under 5 years in tehran, iran, in 2012: a population-based study. Res Cardiovasc Med 2016;5:e30425.

21. Hajian-Tilaki K, Heidari B. Childhood obesity, overweight, sociodemographic and life style determinants among preschool children in Babol, Northern Iran. Iran J Public Health 2013;42:1283-91.

22. Karimi B, Ghorbani R. Overweight and obesity in the Iranian schoolchildren. Middle East J Rehabil Health Stud 2015;2:e24433.

23. Ogden CL, Carroll MD, Curtin LR, Lamb MM, Flegal KM. Prevalence of high body mass index in US children and adolescents, 2007-2008. JAMA 2010;303:242-9.

24. Wang Y, Monteiro C, Popkin BM. Trends of obesity and underweight in older children and adolescents in the United States, Brazil, China, and Russia. Am J Clin Nutr 2002;75:971-7.

25. Mushtaq MU, Gull S, Abdullah HM, Shahid U, Shad MA, Akram J. Prevalence and socioeconomic correlates of overweight and obesity among Pakistani primary school children. BMC Public Health 2011; 11:724.

26. Fallahzadeh H, Saadati H, Keyghobadi N. Estimating the prevalence and trends of obesity in Iran populations from 2000 to 2011: a metaanalysis study. J Shahid Sadoughi Univ Med Sci 2017;25:681-9.

27. de Onis M, Blössner M, Borghi E. Global prevalence and trends of overweight and obesity among preschool children. Am J Clin Nutr 2010;92:1257-64.

28. Dorosty AR, Siassi F, Reilly JJ. Obesity in Iranian children. Arch Dis Child 2002;87:388-91.

29. Kelishadi R. Childhood overweight, obesity, and the metabolic syndrome in developing countries. Epidemiol Rev 2007;29:62-76.

30. Moayeri H, Bidad K, Aghamohammadi A, Rabbani A, Anari S, Nazemi L, et al. Overweight and obesity and their associated factors in adolescents in Tehran, Iran, 2004-2005. Eur J Pediatr 2006;165:48993.

31. Veugelers PJ, Fitzgerald AL. Prevalence of and risk factors for childhood overweight and obesity. CMAJ 2005;173:607-13.

32. Ghassemi H, Harrison G, Mohammad K. An accelerated nutrition transition in Iran. Public Health Nutr 2002;5(1A):149-55.

33. Mohammadpour-Ahranjani B, Rashidi A, Karandish M, Eshraghian MR, Kalantari N. Prevalence of overweight and obesity in adolescent Tehrani students, 2000-2001: an epidemic health problem. Public Health Nutr 2004;7:645-8.

34. Majid A, Mohsen H, Roya N, Mehdi G, Sedigheh M. Incidence in overweight and obesity among schoolchildren, Ahvaz-2010. Jundishapur Sci Med J 2014;12:355-61.

35. Sanigorski AM, Bell AC, Kremer PJ, Swinburn BA. High childhood obesity in an Australian population. Obesity (Silver Spring) 2007;15: 1908-12.

36. Amini M, Omidvar N, Kimiagar M. Prevalence of overweight and obesity among junior high school students in a district of Tehran. J Res Med Sci 2007;12:315-9.

37. Hajian KA, Sajadi P, Rezvani AR. Prevalence of overweight and underweight among primary school children aged 7-12 years (Babol; 2006). J Babol Univ Med Sci 2008;10:83-91. 
38. Demissie S, Worku A. Magnitude and factors associated with malnutrition in children 6-59 months of age in pastoral community of Dollo Ado district, Somali region, Ethiopia. Sci J Public Health 2013;1:17583.

39. Fardazar FE, Mansori K, Solhi M, Hashemi SS, Ayubi E, Shadmani FK, et al. A cross-sectional study for determinations of prevention behaviors of domestic accidents in mothers with children less than 5-year. Int J Pediatr 2016;4:1679-85.

40. Khazaei Z, Khazaei S, Valizadeh R, Mazharmanesh S, Mirmoeini R, Mamdohi S, et al. The epidemiology of injuries and accidents in children under one year of age, during (2009-2016) in Hamadan Province, Iran. Int J Pediatr 2016;4:2213-20.

41. Mansori K, Khosravi Shadmani F, Mirzaei H, Vesal Azad R, Khateri S, Mansouri Hanis S, et al. Prevalence of stunting in Iranian children under five years of age: systematic review and meta-analysis. Med J Islam Repub Iran 2018;32:103.

42. Moradi Y, Shadmani FK, Mansori K, Hanis SM, Khateri R, Mirzaei H. Prevalence of underweight and wasting in Iranian children aged below 5 years: a systematic review and meta-analysis. Korean J Pediatr 2018;61:231-8.

43. Nouri Saeidlou S, Babaei F, Ayremlou P. Malnutrition, overweight, and obesity among urban and rural children in north of west Azerbijan,
Iran. J Obes 2014;2014:541213.

44. Talaie-Zanjani A, Faraji F, Mohajerani HR. The study of obesity and overweight in Arak primary school Students, 2009. J Kermanshah Univ Med Sci 2012;16:174-9.

45. Akhavan-Karbasi S, Fallah R, Golestan M, Sadr-Bafghi M. Prevalence and risk factors of obesity and overweight among primary school children in Yazd. J Shahid Sadoughi Univ Med Sci 2009;16:8-13.

46. Fatemeh F, Mohammad-Mehdi HT, Toba K, Afsaneh N, Sharifzadeh G, Student Research committee. Prevalence of overweight and obesity in preschool children (2-5year-olds) in Birjand, Iran. BMC Res Notes 2012;5:529.

47. Houshiar Rad A, Dorosty AR, Kalantari N, Abdollahi M, Abtahi M. Prevalence of stunting, underweight, wasting and overweight among Iranian under-five-year-old children (2000-2002). Iran J Nutr Sci Food Technol 2009;3:49-56.

48. Nouhjah S, Karandish M, Malihi R, Tamadon F. Prevalence of overweight and obesity in 2-5 years children based on new who growth standards in Ahwaz, Iran. Pediatr Res 2011;70:392.

49. Sharabi M, Zarezadeh M, Nasiri N, Madani L, Minaie M. The prevalence of malnutrition in children with 2 to 6 years in Tehran. Tabriz Univ Med Sci 2005;2:143-51. 